https://doi.org/10.48009/1_iis_2005_265-274

\title{
WEB BASED AFTER-SCHOOL SUPPORT NETWORK FOR SECONDARY SCHOOL MATH AND INFORMATION TECHNOLOGY
}

\author{
A. A. Adekoya, Virginia State University, aadekoya@vsu.edu \\ X. Bai, Virginia State University, Xbai@ vsu.edu \\ F. M. Ikem, Virginia State University, fikem@vsu.edu \\ G. Ola, Virginia State University, Gola@vsu.edu
}

\begin{abstract}
This paper serves as a vehicle for disseminating information and eliciting feedback on a unique and timely pedagogic intervention program. Ultimately, the project is expected to engender and enhance innovative and cooperative learning opportunities for disadvantaged and minority students, particularly African-Americans participating in a DoD funded Science, Mathematics and Engineering (SME) program. The purpose of the project is to provide a support network for year-round after-school learning in Math and Information Technology (IT) in the Richmond, Virginia metropolis. The project which is ongoing, will lead to the implementation of a Web based support network where (i) homework Math and IT projects and assignments are discussed in moderated groups, (ii) students will have the opportunity to review their class work in Math through short self-paced lectures consisting of solutions to sample problems that directly mirror assigned homework, and (iii) students will acquire or enhance their IT skills through directed and self-paced IT courses in computer programming and applications.
\end{abstract}

Keywords: Web-based instruction, Science, Mathematics \& Engineering, co-operative learning, e-learning

\section{INTRODUCTION}

Virginia State University (VSU) is a historically African-American Institute founded in 1882. While continuing its role as a nationally known historically African-American Institute, it has become the regional university for all residents of Southside Virginia.

We share the DoD's program goals of increasing the number of graduates, including underrepresented minorities, in the fields of science, mathematics, and engineering. This project therefore seeks to provide multiple channels and opportunities for pre-college students to acquire a solid background in math and science and for participating students to ultimately succeed in math and science programs. To this end, and to prepare VSU for the technological reality of the new millennium, the project team is currently building an e-learning infrastructure through the development of the repository of reusable learning objects as well as user training.

To achieve the project objectives, a number of innovative and time-tested strategies are employed. Such strategies include the following: 
- A moderator-led, Web-based study group to help middle and high schools students understand and complete assigned homework in math and science courses.

- Supplemental self-paced short lectures providing solutions to sample problems that mirror homework assignments in pre-college and college math and science courses.

- A summer program allowing high-achieving incoming freshmen to supplement their high school electives by completing advance placement equivalent courses in math and computer programming through live web-based classes.

- A prerequisite and concept learning system where college students have been provided access to short lectures and examples on the basic concepts required for core SME courses. Students will be able to assess their readiness for a course and go through online lectures and examples to remedy any deficiencies.

- Redundant online versions of in-class courses to provide college students with a means of reviewing in-class lectures. An online version of a course may consist of either recorded sessions of classes that are conducted using an online presentation software system or a self-paced course that is designed to mirror the instructor-led course.

- Facilitation of discussion and homework groups for core college SME courses using a Web based discussion and study group infrastructure. The best students from previous semesters will serve as homework and discussion group Teaching Assistants (TAs) for future groups of students.

- An automated course development and management tool, including a repository of learning objects and templates, to facilitate the migration of courses online by faculty and to enhance the e-learning technical capabilities of SME departments and the college.

- Provision of training for faculty on migrating their courses online-both instructor-led and online.

\section{REVIEW OF LITERATURE}

Contemporary educators and education practitioners have over the last few decades been debating the appropriateness and the role of instructional technology and, most particularly, information and communications technology. The last several years have heralded and witnessed the development of two dominant trends with unprecedented effects on the course of educational technology: an increase in the number and types of technology resources available and dramatic shifts in beliefs about fundamental goals and strategies of education itself [6]. Considering the fact that the primary goals of education have begun to change as dictated by new and emerging social and educational needs, teaching strategies exemplified by the integration of technology into teaching and learning, also are changing [8].

A powerful medium in this new and profound arena is the Internet and its almost inseparable adjunct, the graphical-based access called the World-Wide-Web. This project, while taking advantage of the dividends of the advances of collaborative learning, will in no small scale, also harness the power of online instruction. The literature is replete with a variety of examples and a variety of models $[4,2,7,3]$.

\section{Redundant Learning Systems}

The principal focus of the entire project, has been the development and maintenance of the redundant learning system. In the best traditions of online pedagogy and drawing from best- 
practices examples [8, 5], the proposed system provides an Advanced Self-paced Learning Environment (ASLE) through the Intelligent Self-paced Learning Agent, which is accessible from any location using web browsers. The Secure Internet-based File Management System allows access to shared files and collaboration. The four main components of the system are the Course Template Library, Courseware Repository, a Courseware Development, and Courseware Design Tools that collectively, facilitate course and content development.

Figure 1 below gives a schematic of the dynamics and the interrelationships among the various component parts of the Advanced Self-paced Learning Environment.

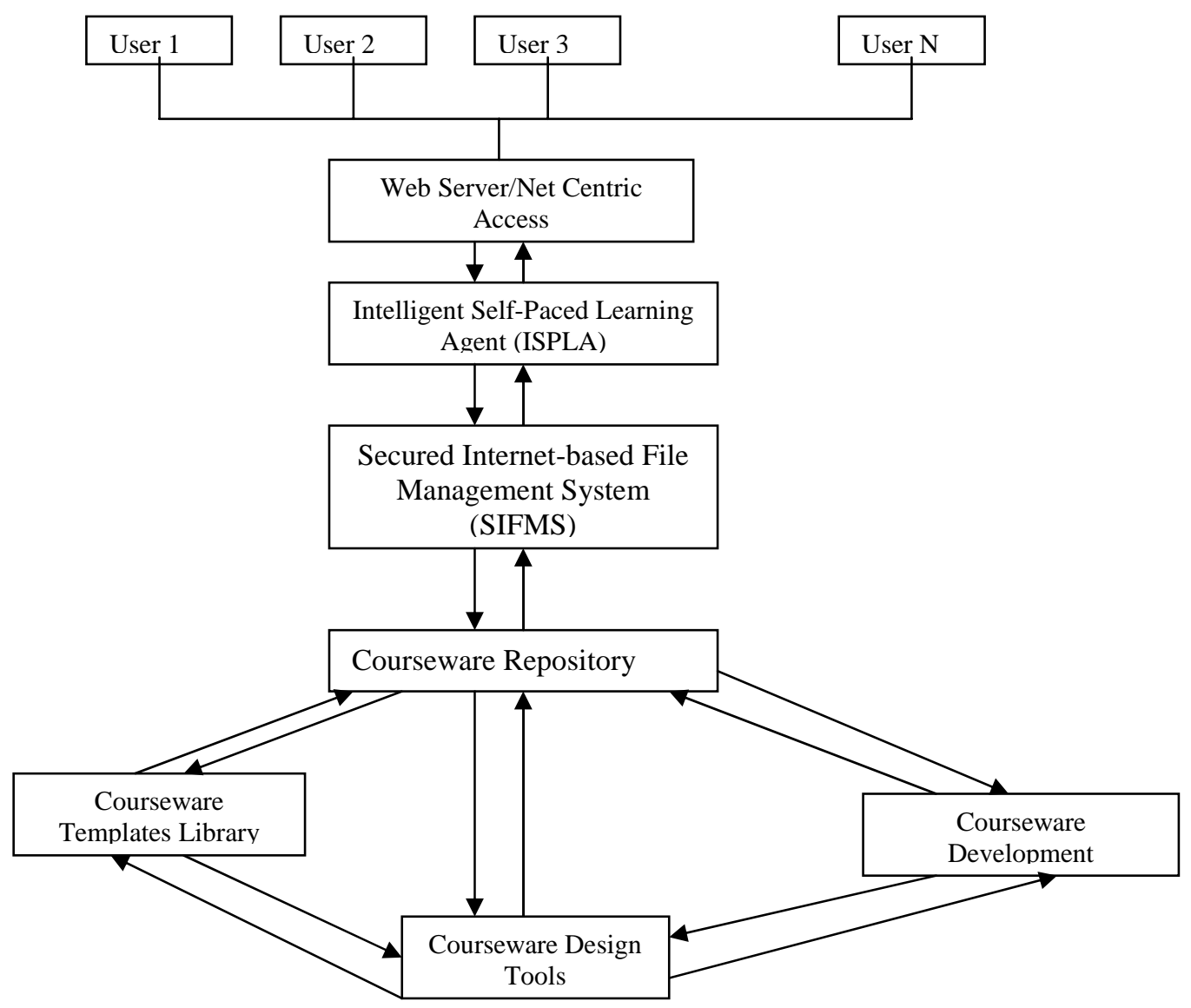

Figure 1. System Architecture for Advanced Self-paced Learning Environment (ASLE)

ASLE depicted above consists of the following components: Web Server, Intelligent Self-paced Learning Agent, Secured Internet-based File Management System, and Course Management System. The course management system consists of courseware repository, templates library, design tools, and courseware development components.

The Web server provides services so the system can be accessed through the Internet. It also provides secured access, so only authorized users can access the system. The Intelligent SelfPaced Learning Agent (ISPLA) provides access to courses, lessons, on-demand lectures which 
may be tied to defined learning objectives. The system consists of an intelligent control mechanism to ensure that learners reach certain levels of proficiency. The Secure Internet-based File Management System (SIFMS) is a distributed file management system that allows users to store their documents on any specified computers. It also allows collaboration and access to shared files and documents. It allows documents to be made available to individual users or user groups. It is a virtual file system where the images of files and documents are presented on users' browser windows. Users with appropriate authorization can access the various files and documents, and can also perform various functions such as copying or moving the files. SIFMS provides three levels of security. The first level of security is provided through the virtual/image file system which shields the actual locations of files. Typical shared files and documents will be located on systems across the intranet or the Internet. The next set of security is achieved through encryption and access authorization system. The last layer of security is provided through the access tracing system which tracks users' access to the documents and files. The Course Template Library includes a database of reusable learning objects and templates to facilitate the design of SCORM and non-SCORM conformant content repositories. It works with a format conversion system to support customization of information based on domain. The courseware design tool is to facilitate courseware development process by using template library.

Figure 2 below shows a step-by-step implementation of the Intelligent Self-Paced Learning Agent (ISPLA). It presents in brief, the sequential process by which students interact with the system.

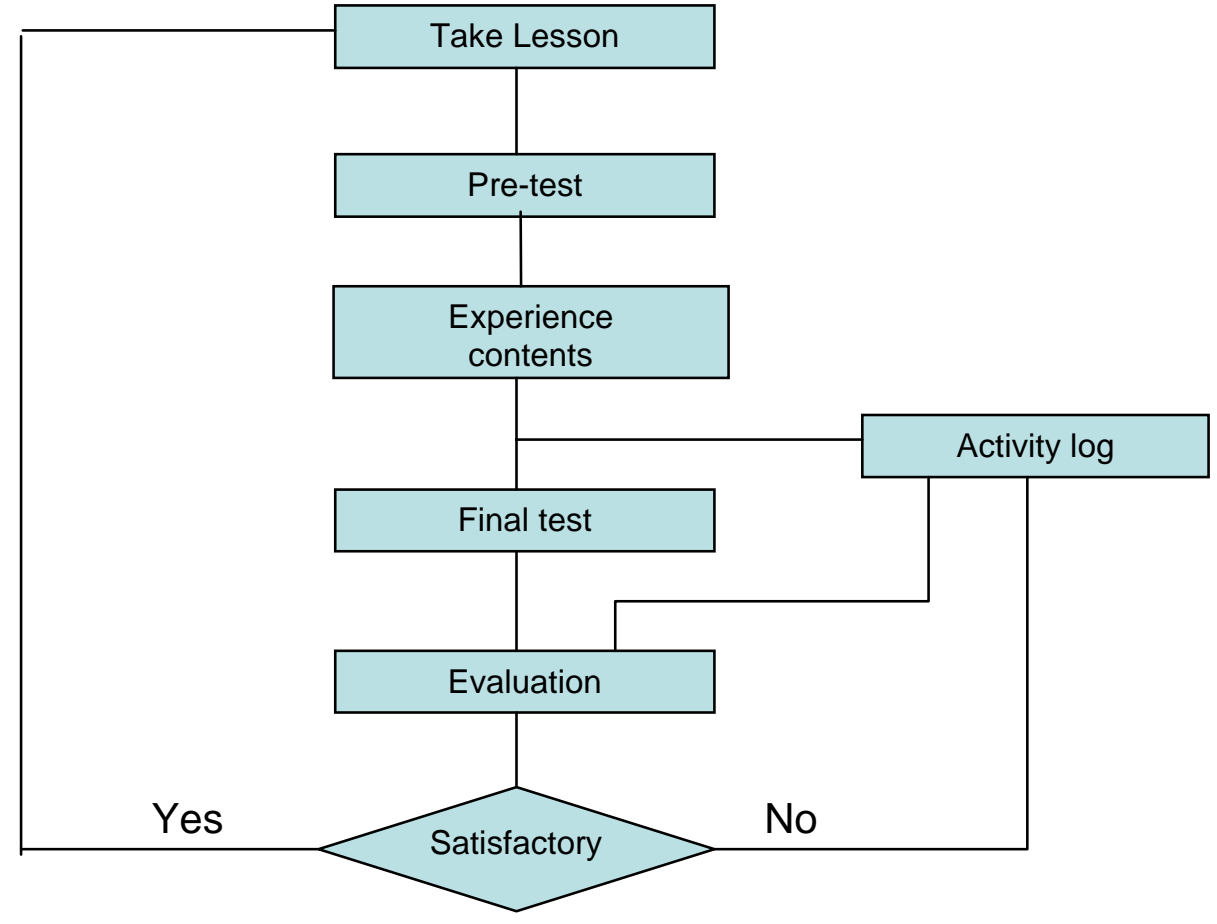

Figure 2. Intelligent Self-Paced Learning Agent (ISPLA) 
In order to fulfill the terms of the grant as articulated in the proposal, certain critical objectives are being implemented. Significant progress has been achieved along these lines as we approach the end of the second funding year. Toward this end, we have developed a Web based OnLine Instance Presentation System (OLIPS) for the virtual classroom.

OLPIS is a live presentation system via the Internet that allows a moderator and students to control what is displayed on all participants' desktops. For a particular connect session, the teacher/moderator will explain concepts, answer questions, and model sample problems for the homework. Each session will be recorded to allow students subsequent access. The recorded session will also serve as a mechanism for control and monitoring of the group's activities. We are currently working with selected schools to provide students with access to computers. As part of the learning infrastructure to be implemented under this project, students will be able to dial into servers in the lab to gain Internet access. The test run would help determine the optimum number of students to be assigned to a group. The interface to OLIPS, is presented in Figure 3 for reference.

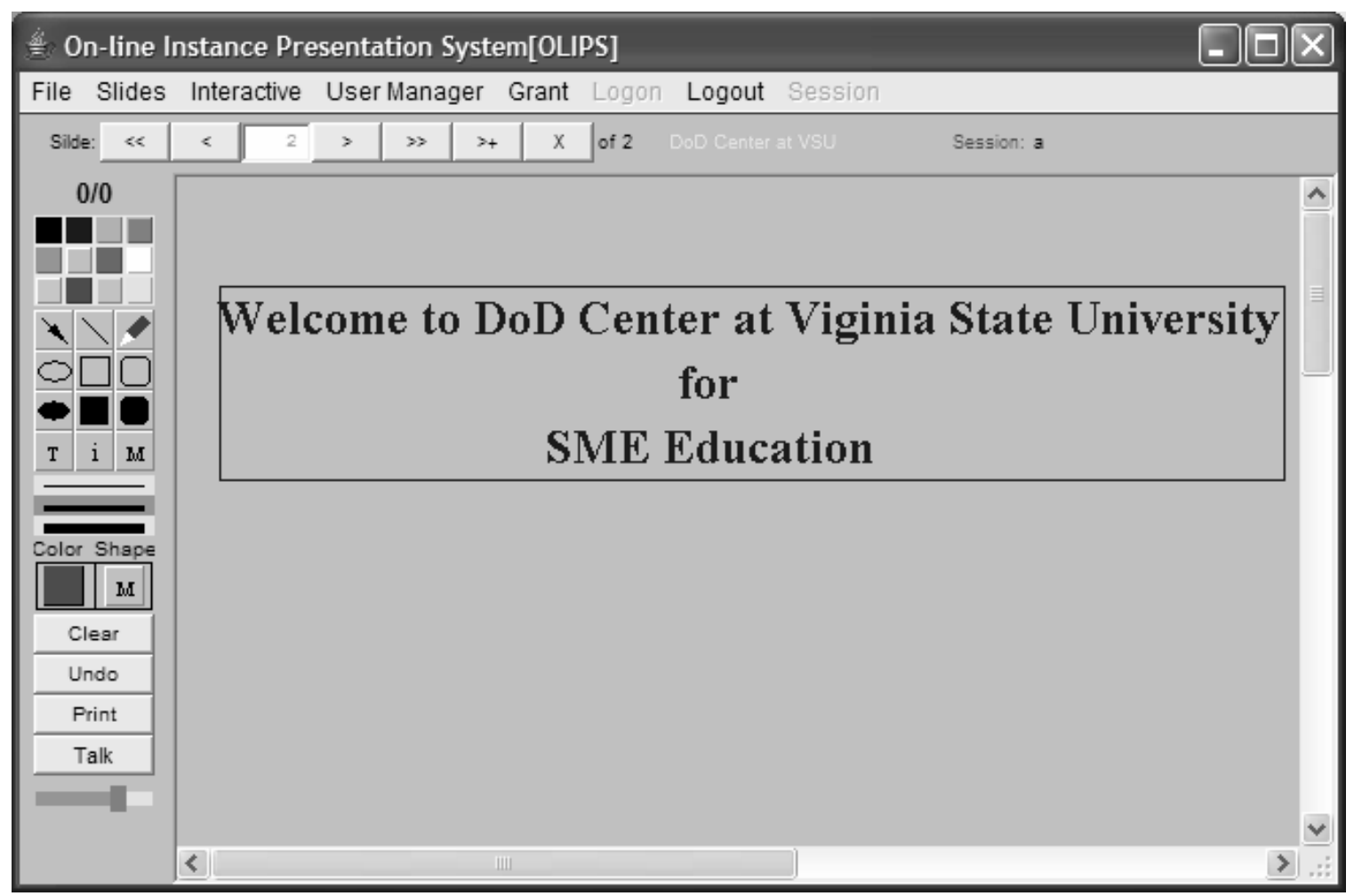

Figure 3. OLIPS system

The provision of outside-the-classroom learning environment through supplemental self-paced short lectures for middle- and high school students were effected using two state-of-the-art softwares; namely, Online Presentation Software (OLIPS) and a commercial productViewletBuilder-will be used to implement the short lectures. ViewletBuilder is suitable for short online lectures, while OLIPS will provide the environment to play back recorded live lectures. 
This learning environment has provided a powerful resource for local schools to refer students needing after-school help in specific courses in math and science. This learning environment is invaluable in many ways. First, to teachers who can refer students to review course materials after the regular class meetings, and to students requiring supplemental instruction and homework's support. The environment can also be useful to parents and guardians who wish to be actively involved in the education of their wards.

Redundant online versions of in-class courses will provide college students with a means of reviewing in-class lectures. An online version of a course will consist of either recorded sessions of classes that are conducted using an online presentation software system. OLIPS will be the implementation platform. Selected sections of core courses will be conducted using OLIPS to have a record of each meeting. The presentation software allows indexed access to different points of a recorded session. The recorded classes will be available via the Internet or in CD format.

We have also developed a Course Management System (CMS) that allows customizable Web environment for online and distance learning. The system includes different modules covering the test bank, file management, content design, communications, class work management, assessment, and user administration. The slide below speaks to the attributes, functionalities, as well the available options made available on the Web Course Management System.

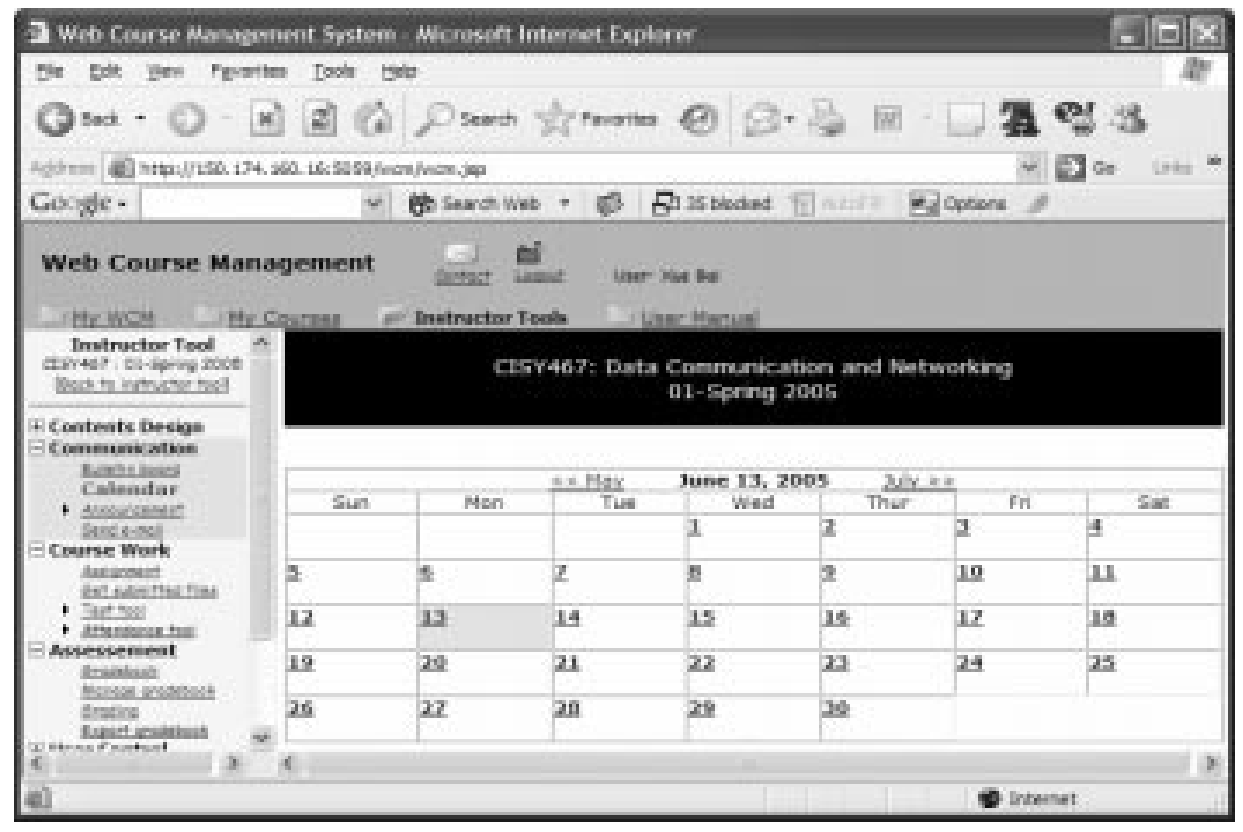

Figure 4. Web Course Management System

Plans are underway to implement an automated course development and management tool, including a repository of reusable learning objects and templates, to facilitate the migration of courses online by faculty and to enhance the e-learning technical capabilities of SME departments and the college. The tools and templates will provide semi-automated mechanisms 
for instructors to post and distribute syllabi, announcements, homework assignments, and course content.

\section{CONCLUSION}

Experience to date suggests that the drive and the apparent shift to web-based course management and delivery systems will include difficulties which are replete and similar to our ongoing existing project; namely the administrative, organizational, and personnel issues that present themselves more difficult than the technical problems we anticipated.

In spite of these shortcomings, we at the end of this project, aim to have implemented a novel approach and prototype for offering and lending homework support for needy high school students over the ubiquitous World-Wide-Web. The web is a tool, which recognizes the complexity of instruction delivery, and yet practitioners persist with a gross simplification of the concept in some of its practical applications. If successful, this project will add knowledge on how to effectively, deliver online course instruction and to use the web, to significantly, improve teaching and learning. The Web based model has the potential for remedying, in a radical way, the disadvantages students suffer from lack of academic guidance in the home.

This support network would also be invaluable to teachers who can refer students to review materials that are accessible after the regular class meetings, to students requiring supplemental instruction and homework support. Moreover, and in line with Callahan et. al. [1] assertions, caring parents and guardians who wish to be actively involved in the education of their wards can employ technology as in this particular example to their advantage.

\section{REFERENCES}

1. Callahan, K., Rademacher, J., \& Hildreth, B. (1998). The effect of parent participation in strategies to improve the homework performance of students who are at risk. Remedial and Special Education, 19.

2. Chickering, A. W., \& Ehrmann, S. (1996). Implementing the Seven Principles: Technology as Lever, AAHE Bulletin, 49(2).

3. Dixon, Robert S. (2000). Internet Videoconferencing: Coming to Your Campus Soon, EDUCAUSE Quarterly, (4), 22-27.

4. Ehrmann, S. C., \& Collins, M. (Sept. 2001). Emerging Models of Online Collaborative Learning: Can Distance Enhance Quality? Educational Technology Magazine.

5. Pelz, B. (June, 2004). My Three Principles of Effective Online Pedagogy, Journal of Asynchronous Learning Networks, 8.

6. Robyler, M.D., Edwards, J. \& Havriluk, M.A. (1997). Integrating Educational Technology into Teaching, Upper Saddle River, NJ: Merril.

7. Roschelle, J. (1996). "Learning by Collaborating: Convergent Conceptual Change". In T. Koschman (Ed.) CSCL: Theory and Practice. Mahwah, NJ:LEA.

8. Salend, J.S., Duhaney, D., Anderson, D. J. \& Gottschalk, C. (2004). Using the Internet to Improve Homework Communication and Completion, Teaching Exceptional Children, 36(3).

9. Smith, N. (May/June 2002). Teaching as Coaching: Helping students learn in a technological world, EDUCAUSE Review.

Supported by DoD Grant. Grant No. W911NF-04-1-0027 